\title{
EDUCACIÓN, CULTURA Y SUPERVIVENCIA
}

Ruy Díaz Díaz

Honduras

\section{INTRODUCCIÓN}

La aparición del homo sapiens sapiens, su vinculación con el desarrollo de la cultura, el surgimiento de la enseñanza y de la educación y la pertinencia o no del proceso educativo en la sobrevivencia humana, son los temas que se abordan en el presente trabajo.

Para nuestro interés citamos a Moore (1999:60) que afirma "Enseñar es tener la intención de que alguien aprenda algo" y a Savater (1997:41) que al referirse a los procesos de enseñanza y educación establece "El hecho de que cualquiera sea capaz de enseñar algo a alguien en su vida... no quiere decir que cualquiera sea capaz de enseñar cualquier cosa"

Para Moore (1999:62) "No toda enseñanza es educación. La enseñanza es una condición necesaria para la educación, pero no suficiente" y Savater (1997:41) al respecto indica "La institución educativa aparece cuando lo que ha de enseñarse es un saber científico, no meramente empírico y tradicional" y posteriormente agrega, también refriéndose a la educación "...ese proceso de enseñanza nunca es una mera transmisión de conocimientos objetivos o de destrezas prácticas, sino que se acompaña de un ideal de vida y de un proyecto de sociedad" (Savater, 1997:145) Por su parte Camps (1997) afirma que la función de la educación: "no es solo instruir o transmitir conocimientos, sino integrar en una cultura, que tiene diferentes dimensiones, una lengua, unas tradiciones, unas creencias, unas actitudes, unas formas de vida ..."

Asimismo, asumiremos en lo sucesivo el concepto de cultura que “... designa el proceso mediante el cual una disposición y habilidad de comportamiento pasa de una generación a otra mediante procesos de aprendizaje social” (García y García, 2001:370)

La forma de delimitar el conocimiento científico, frente a otros tipos de conocimiento es un problema no resuelto definitivamente, mientras la posición racionalista sostiene que la diferencia entre la ciencia y otros tipos de conocimiento es su posibilidad sistemática de ser rechazada por los datos de la realidad; el enfoque empírico-inductivo apunta que un enunciado es científico en la medida en que su VERACIDAD pueda ser confirmada por la experiencia. En cualquier caso, el conocimiento científico se caracteriza por ser sistemático y según Ortiz (1997) sus pretensiones de validez están definidas por el potencial de razones que lo hacen aceptable.

Por su parte, la tecnología es un concepto casi siempre ligado al de la ciencia y por lo tanto también en construcción y según Acevedo (1998) no es sinónimo de ciencia aplicada. En la tecnología han pervivido algunas características específicas de oficios tradicionales, conocimientos tácitos y habilidades técnicas que han dado respuesta a algunas necesidades humanas (Acevedo, 1998). 
Que la educación cumplió en el pasado un rol decisivo en la supervivencia de nuestra especie, no es aspecto a debatir, el aspecto discutible es sí todavía lo sigue jugando en nuestro presente, en el ámbito del desarrollo científico y tecnológico que caracteriza nuestro tiempo.

Se conocen (Ángela \& Ángela, 1999) entre 10 y 15 especies de bípedos humanoides; Austrolopitecus y homínidos y al menos dos especies de homo sapiens (el homo sapiens sapiens y el hombre de Neandertal) que han deambulado sobre nuestro planeta.

Refiriéndose al sapiens sapiens, García \& García (2001:374) apuntan que "La adaptación fundamental de la especie humana ha sido la capacidad de objetivar la experiencia y preservarla en la cultura... y de convertir en proyecto y en proceso de incorporación de los bienes culturales a la actividad mental...."

Sí señalamos como criterios de cultura la innovación, la difusión, la estandarización, la estabilidad, transmisión generacional, tradición, espontaneidad e irrelevancia biológica, entonces, según Sagan \& Druyan (1993:354) varias especies de primates que conviven con nosotros en la actualidad, poseen cultura.

En la definición de Lowy (1999) de cultura, valida únicamente para nuestra especie, se incorpora un elemento importante: "Es la necesidad y la capacidad de expresar el propio devenir a través del atributo de la imaginación, exclusivo de la especie."

Postulamos que, aunque se puede hablar de la cultura de humanoides previos al homo sapiens sapiens, solo se puede hablar de educación en el homo sapiens sapiens, que surge gracias a la capacidad, específicamente humana, de imaginar la forma en que va a reaccionar un par ante un estímulo determinado, es decir, debido a la capacidad específica que tienen los seres humanos de reconocer estados interiores en la mente de sus interlocutores, y que ese proceso tiene como finalidad su pervivencia como especie.

\section{RAÍCES DE LA EDUCACIÓN.}

El homo sapiens sapiens es uno más de los varios millones de especies que cohabitan en el planeta y por tanto, no es ajeno a las leyes evolutivas que rigen la pervivencia de las mismas en función de la capacidad de adaptación al ecosistema y formación de un nicho ecológico.

En el segundo capítulo de El Origen de las Especies (La lucha por la supervivencia) Darwin (1859) afirmó que las variaciones, por ligeras que sean, si en alguna medida son provechosas para los individuos, en general, serán heredadas por la descendencia. Asimismo, "El medio ambiente selecciona aquellos individuos mejor adaptados para sobrevivir, mientras que las variantes individuales menos adaptadas no llegan a reproducirse" (Savage, 1987:36) de ahí que, en sus orígenes, la cultura debe haber tenido ventajas biológicas adaptativas en los seres vivos que la desarrollaron; como la producción de capacidad de invención de comportamiento, la superación ventajosa de las peligrosidades del entorno; la capitalización, en beneficio propio, de la experiencia de otros y la explotación de nuevos nichos ecológicos.

El homo sapiens surge cuando dentro de los homínidos se gestó la conciencia de la muerte y la idea de su trascendencia, cuya manifestación conductual se refleja en el entierro de los muertos (Ángela y Ángela, 1999:612). Lo irónico resulta en que, como consecuencia del proceso evolutivo que nos convirtió en seres racionales, lleguamos a ser sapiens, en el momento en que irracionalmente (por fe), como especie, aceptamos la existencia de la vida después de la muerte. 
En Europa y África se desarrollaron, casi simultáneamente, dos líneas paralelas de homo sapiens: El hombre de Neandertal (hace 250000 años) y el homo sapens sapiens (hace 150000 años) respectivamente, “. . a a fin de responder a la exigencia ambiental de seleccionar individuos dotados de cerebros más grandes, capaces de mejorar la propia supervivencia a través de una mayor inteligencia, organización y lenguaje...." (Ángela y Ángela, 1999: 648). El homo sapiens sapiens emerge con la aparición de la capacidad de imaginación, cuya expresión cultural mejor documentada es el arte.

El homo sapiens sapiens en tanto especie y sujeto educable ha subsistido y progresado debido a la capacidad mental de investigación, cuya realización ha dotado a la humanidad de recursos mayores y más eficaces de defensa contra todo tipo de adversarios, de medios de superación de obstáculos y de conquista de logros para perfeccionar formas de alimentación y convivencia humana, lo que ha tenido su génesis en la fabricación y manipulación de herramientas.

El sapiens sapiens no fue el primer homínido en fabricar herramientas. Por cuanto "La manipulación de herramientas y su construcción se hacen posibles por la posición erguida..." (Savage, 1987:183) se comprende que diferentes especies de homínidos han elaborado instrumentos, artefactos, costumbres, normas, códigos de comunicación y convivencia como mecanismos imprescindibles para la supervivencia de sus grupos y especies.

Aunque Gimeno Sacristán y Pérez Gómez (1998:17) hacen la siguiente aclaración, refiriéndose a una significativa diferencia del homo sapiens sapiens con respecto a otros hominidos:

... a partir del hombre, las adquisiciones adaptativas de la especie a las peculiaridades del medio ya no se fijan biológicamente ni se transmiten a través de la herencia genética. Los grupos humanos pusieron en marcha mecanismos y sistemas externos de transmisión para garantizar la pervivencia en las nuevas generaciones de sus conquistas históricas. A este proceso de adquisición por parte de las nuevas generaciones de las conquistas sociales y de socialización a fin de moldear conductas que garanticen la supervivencia, se le denomina genéricamente como proceso de educación.

En nuestra perspectiva, la noción de la supervivencia en tanto que razón de ser de la educación, se diluye y se confunde en el currículo con los requerimientos de producción, dominación, cultura etc. debido a la "...aceleración del desarrollo histórico de las comunidades humanas, así como al enmarañamiento de las estructuras y la diversificación de funciones y tareas de la vida." (Gimeno Sacristán y Pérez Gómez, 1998:17), que requieren de resolución de problemas ingentes no vinculados, aparentemente, a la supervivencia.

En los grupos humanos pequeños y en las sociedades primitivas el proceso de transmisión de conocimientos se presenta mediante procesos de socialización primaria que incluyen la participación cotidiana de los niños/as en las actividades de la vida adulta a través de las células primarias de convivencia: la familia, el grupo de iguales, los centros o grupos de trabajo y producción (Gimeno Sacristán y Pérez Gómez, 1998:17)

Pero, en las sociedades complejas, el hombre (homo sapiens sapiens) requiere del conocimiento científico y tecnológico, desarrollando para ello (Gimeno Sacristán y Pérez Gómez, 1998:17) “...diferentes formas de especialización que desembocaron en el proceso de educación o socialización secundaria (tutor, preceptor y escuela) que han conducido a los sistemas de escolarización obligatoria para todas las capas de la población en las sociedades contemporáneas." 
De esta forma se explica y justifica plenamente la aparición y la existencia de la educación, vinculada al proceso productivo, sobre la base del requerimiento de la enseñanza del conocimiento científico y tecnológico.

\section{LO HUMANO ES LA PERTENENCIA A LA ESPECIE SAPIENS}

La resistencia a reconocer que el sentido de la educación es la supervivencia de la especie humana nace de la presunción de una inteligencia superior producto del tamaño significativo del cerebro humano, con respecto al de las demás especies con las que se cohabita en este planeta, y de la presunta capacidad racional del homo sapiens sapiens para aprender.

Con respecto al cerebro, García y García (2001:199) escriben:

Desde el punto de vista evolutivo el cerebro se desarrolló para asegurar la sobrevivencia corporal y no para realizar cálculos algebraicos, tomar decisiones racionales o mantener recuerdos imborrables. Cuando los cerebros evolucionaron hasta producir pensamiento se encontró ventajoso pensar en la situación para actuar sobre ella. Esta capacidad junto al hecho de asumir socialmente ese cometido es lo que posibilita y origina la cultura.

A pesar de que la lucha por la supervivencia es una conducta propia de todas las especies, y en ese sentido el desarrollo del cerebro y/o de la inteligencia no garantiza la persistencia del homo sapiens sapiens, y aun cuando se sabe que el elemento que lo distingue sustancialmente de otras especies y lo define es la capacidad para reproducirse entre sí, que es a final de cuentas lo que diferencia una especie de otra, Sagan \& Druyan (1993:353) observan que “... casi todos los grandes pensadores occidentales; Platón, Aristóteles, Marco Aurelio, Agustín, Tomas de Aquino, Leibniz, Kant, Comte, Hegel, Rosseau, y muchos otros; han planteado que el homo sapiens sapiens es fundamentalmente diferente del resto de los formas vivientes."

Este enfoque se refleja, por un lado, en la posición central que tiene el hombre en las concepciones religiosas, justificada en la creencia de que somos el producto supremo de la creación y, por otro lado, en el lugar terminal que se otorgó al hombre en la concepción evolucionista tradicional que consideró, por mucho tiempo, que el fin de la evolución es el hombre, y que puede tener su razón de ser en la búsqueda de un argumento que justifique doblegar al resto de los seres a nuestra voluntad, conseguir que trabajen por nosotros y/o comerlos sin ningún sentimiento de culpa.

La argumentación anterior permite afirmar a Sagan y Druyan (1993:354) que "...con nuestras conciencias tranquilas podemos extinguir especies enteras en nombre de un beneficio, algunas veces imaginario, a corto plazo" y agregan, ya en lo referente a lo estrictamente humano: "Uno de los intentos más antiguos por caracterizar a la humanidad fue dado por Platón quien llegó a plantear que el hombre es un 'bípedo sin plumas'". Cuando Diógenes (el de la lámpara, encendida durante el día; el del barril empleado como vivienda; el que cuando pasó por el mercado se alegró, al ver tantas cosas que no necesitaba) tuvo conocimiento de esta definición, "....introdujo un pollo desplumado a a Academia de Platón y pidió a los estudiosos reunidos que saludaran al 'hombre de Platón'". (Sagan y Druyan 1993:355)

La definición platónica, en sustancia, sostiene que es la condición bípeda la que nos hace diferentes, sin embargo, ésta, aunque es una condición necesaria, no es suficiente. Efectivamente, "...requerimos del bipedismo para tener las manos libres a fin de desarrollar tecnología" (Savage, 1987:187) y se ha argumentado erróneamente que es precisamente la capacidad para generar herramientas de trabajo lo que nos distingue por cuanto hay suficiente evidencia de que mapaches y marmotas de las praderas 
tienen manos y carecen de tecnología, mientras los bonobos caminan de pie durante una buena parte de sus vidas y los chimpancés disponen de tecnología y no son bípedos.

Sagan y Druyan, (1993:355) al abordar el tema de lo exclusivamente humano en algunos pensadores, bajo la óptica de la economía recapitulan:

Adam Smith en su justificación del capitalismo de libre empresa afirma que 'la propensión a los tratos, al trueque, a cambiar una cosa por otra... es común de todos los hombres y no se da en ninguna raza de animales'. Martín Lutero propuso en el siglo XVI que la propiedad privada era lo que distinguía esencialmente a los hombres de los animales y similar razonamiento presentó el Papa León XIII en el siglo XIX.

Como contra argumento a lo propuesto por Smith y Lutero, se puede hacer referencia a los chimpancés a quienes les gusta el comercio: comida a cambio de sexo, masajes en la espalda a cambio de sexo, traicionar al dirigente a cambio de sexo, no mates a mi hijo a cambio de sexo. La comida y algunas herramientas participan del concepto rudimentario de propiedad privada (Sagan, y Druyan, 1993:357)

El egoísmo, la explotación y el trueque son corrientes en la vida de los chimpancés, pero no podemos explotar lo afirmado y nuestro parentesco y similitud genética de más del 95\% (Ridley, 2000:63) con éstos simios para justificar la economía de "dejar hacer dejar pasar" (esencia del capitalismo), ni tampoco podemos utilizarla para desacreditar las economías de libre mercado aduciendo que son simiescas..... ¿O si?

En Henríquez, (2003) encontramos una tesis sustentada en habilidades cognitivas, con relación a lo específicamente humano:

Lo que nos distingue del resto de los seres vivos es nuestra habilidad para usar y transmitir conocimientos. El hombre de Neandertal se vuelve una especie en extinción en el momento en que el homo sapiens sapiens empieza a dibujar sobre paredes de las cuevas, iniciando así la transmisión de conocimientos en un alfabeto no abstracto, muy difícil de estandarizar, no portátil, que difería de tribu a tribu y de clan a clan, pero que transmitía suficiente información para poderle decir a sus hijos, a sus nietos que "Esta es una de las maneras de ver el mundo" y era una manera eficaz de transmitir conocimientos.

Y Lozano (2003), en una dirección similar añade “... realmente lo propio del sujeto humano es la capacidad de tener consciencia de sí mismo, que lo hace a través del instrumento de objetivación del lenguaje, construido según el referente cultural".

Sin embargo, las habilidades señaladas por Henríquez (2003) y Lozano (2003) se desprenden de nuestra condición de pertenencia a una especie: el homo sapiens, sub especie: sapiens sapiens. Ridley (2000:57) apropiadamente señala que los seres humanos son únicos y poseen la maquinaria más compleja de la naturaleza, el cerebro; aunque la complejidad no es objetivo de la evolución y cada especie es única, por ello concluye que lo único es algo que abunda mucho.

\section{EL APRENDIZAJE, LAS EMOCIONES Y LA IMITACION}

Martínez (1999) afirma que "El hecho de establecer vínculos entre los símbolos de origen material y el pensamiento, marcó un paso decisivo en la evolución del homo sapiens" con lo que cambió toda nuestra estructura psicológica. Lozano (2003) agrega: "El desarrollo del aparato neurocerebral ha contado con la afectividad, como motor para dicho desarrollo, por eso cuando se habla de subjetividad, generalmente se refiere a lo emocional, a los sentimientos..." 
Es, entonces, la creación de novísimos sistemas de comunicación, producto del desarrollo de un cerebro racional-emocional lo que posibilitó la acumulación de experiencia y la transmisión de conocimientos con la finalidad de modular determinados comportamientos, ligados a la supervivencia, donde se encuentra el origen de la educación.

Sobre este punto García y García, (1997:372) observan (refiriéndose al homo sapiens sapiens) que "La modalidad de configuración del comportamiento en la situación, la decisión de acción, el sistema mental que la evolución ha dispuesto opera con finalidad predominantemente adaptativa y de integración con el entorno vital en el que ha de sobrevivir..." Y, Gonzáles, (2004) es contundente al referirse al rol de la educación como "... la herramienta que tiene el ser humano para cumplir su fin como todo ser vivo: sobrevivir; tanto en un medio físico (la naturaleza) como en un medio social (la sociedad) al proporcionar inteligencia (capacidad para pensar y sentir)" y aunque se debe señalar que la educación no es un acontecimiento evolutivo se debe advertir que "... la educación como necesidad y actividad de estructuras es resultado evolutivo, y, como suceso, es un acontecimiento individual con mediaciones sociales sin huella en el código genético..." (García y García, 2001:122)

Tenemos que, mientras las necesidades primarias de nuestra especie y los caracteres fundamentales de las estructuras que soporta nuestro comportamiento se configuraron dentro de una escala evolutiva, las necesidades que surgen en la dinámica de cambio social pertenecen a la escala de tiempo histórico y de evolución cultural.

Savage, (1987:190) es pertinente cuando nos recuerda que la evolución cultural no es biológica "...Cada generación de la humanidad pasa a su predecesora información relacionada con el medio ambiente, las relaciones sociales y la tecnología. En su más pura expresión, la evolución cultural en los humanos se realiza por imitación".

$\mathrm{Y}$, se concluye, las raíces del aprendizaje son tanto racionales como afectivas, con lo que se explica, en parte, que otros seres vivos aprendan, (aunque solo el sapiens sapiens enseña y aprende conocimiento científico, se forma un ideal de vida y un proyecto de sociedad y por ende se educa) ; "...la componente afectiva es esencial en la configuración de todo tipo de actitudes, y de aptitudes, incluidas las intelectuales" (García y García, 2001:326) de ahí se revela que los primates (incluido el sapiens sapiens) aprenden (modifican patrones de conducta) porque desean ser como las relaciones de parentesco lo determinan, en función de la vinculación y adhesión afectiva, que donde es más fuerte es en la relación madre - hijo.

El manejo de herramientas define, en gran medida, las formas como nos relacionamos con el ecosistema y Medina (1999) puntualiza que también "la conciencia o el pensamiento se regulan por el manejo de utensilios, pero no son físicos, su carácter es psicológico: los signos."

Martínez (1999) al analizar los procesos mentales desde el punto de vista de la evolución de las especies (dominio filogenético) se refiere como aquel que "... se centra en el estudio de la forma en que surge una determinada función psicológica en la especie humana... En la filogenia la fuerza principal que interviene es el principio darviniano de la selección natural...".

Por su parte, el estudio de los procesos mentales desde el punto de vista del desarrollo del individuo de embrión a estado adulto (dominio ontogenetico) es mediado por el desarrollo histórico cultural y se advierte la formación sistemática de estructuras, resultado de la asimilación de los productos de la cultura 
humana: “... las funciones mentales o psicológicas que, inicialmente, son elementales (naturales), son mediadas en el proceso de actividad y contacto social con otros seres humanos, mediante un elaborado sistema de signos." (Vila, 1985)

Es decir, en el desarrollo ontogenético de un individuo convergen la maduración orgánica, su historia cultural y su estructura genética. En el desarrollo cultural se crean instrumentos que, sin tener consecuencias biológicas, amplifican las capacidades naturales (biológicas) con que cada individuo está dotado. Por tanto, el paso de lo natural (biológico) a lo cultural queda mediado por el conjunto de artificios convencionales y arbitrarios que la especie humana (y otras especies de homínidos) ha elaborado, en el transcurso de las relaciones e intercambios sociales de sus miembros.

Estos instrumentos son, fundamentalmente, signos y por tanto están investidos de significación y su empleo no implica únicamente una adaptación pasiva al medio, sino un principio de transformación. La actividad humana se caracteriza por modificar y transformar la naturaleza, yendo más allá de una simple adaptación pasiva.

Es por lo anterior que, si bien algunas conductas pueden ser descritas como respuestas del organismo a diferentes estímulos, aquellas conductas que implican un principio de actividad y que están reguladas por los procesos psicológicos superiores se escapan a esta concepción y, para su explicación, se requiere introducir la noción de significación.

Vila (1985) asevera que los signos son establecidos en relaciones sociales, accesibles desde fuera, a través de otro y cada infante los adquiere para regular sus intercambios sociales, mientras los va interiorizando progresivamente hasta que de ser instrumentos para planificar y regular los intercambios sociales pasan a ser instrumentos para planificar y regular la propia conducta. Luego entonces, la conciencia no aparece como algo sobreañadido a la naturaleza humana, sino que resulta ser un producto cultural, sometido a las leyes de la evolución que se define como el contacto social con uno mismo.

\section{EDUCACION Y LA AMENAZA A NUESTRA PERVIVENCIA}

Savater (1996) al referir una posible teleología de la educación escribe que su finalidad "... es formar seres humanos y los seres humanos somos ante todo seres racionales. La razón no es una disposición automática, sino un logro social, posibilitado por unas capacidades naturales y evolutivas." Pero, debemos recordar que nuestra estructura mental además del componente racional lleva inherente el componente emocional. García y García (2001:327) afirman que “... debemos tomar en cuenta que el sistema regulador emocional se sitúa en el origen del desarrollo como mecanismo primario para orientar la atención."

Además, aunque la educación es un accionar específicamente humano, por tanto conciente, no se puede afirmar, para efectos de este trabajo, que tenga como finalidad desarrollar sus propias potencialidades; sino que el desarrollo de esas potencialidades le permite superar los constantes obstáculos a su pervivencia. Lo anterior no es incompatible con aseverar que la educación es proceso, resultado y proyecto (simultáneamente) de cambios de conducta, culturales, sociales y de realización personal.

Bajo la misma línea de pensamiento se concuerda con que "La educación no crea al hombre sino que le ayuda a crearse a si mismo" (Debesse, citado por Mondragón, 1997) pero solo en función de los requerimientos de supervivencia como especie. El hombre es una unidad viva cuya razón de ser es la 
pervivencia, lo que se ha logrado, hasta ahora, a consecuencia, en gran medida, de los procesos educativos; de ahí que la afirmación de Platón de que educar es dar al cuerpo y al alma la belleza de que son susceptibles, no es congruente con el fin de la educación (la supervivencia de la especie), sino que estos son una consecuencia colateral.

Más apropiada, desde nuestra perspectiva, es la posición de Valle (1829, en recopilación de Bardales, 1994) de que "Educar es formar un ser que no existía del modo que se ha formado, es darle conocimientos útiles y hábitos morales que exige su conservación y perfección", eso si, conservación en tanto especie y perfección en tanto individuo.

Asimismo, discrepamos con Fernández (2001) cuando sostiene que "...educarse hoy exige adaptarse cultural, social, laboral y profesionalmente al ritmo de cambio, cifrado en claves de nuevas concepciones culturales, de producción, de relaciones sociales, económicas e industriales.", por cuanto se pierde la noción de que somos una especie, entre millones, que pertenecen a un ecosistema y esa adaptación cultural, social y laboral a las relaciones económicas y sociales nos ha colocado en una situación muy peligrosa desde el punto de vista de la pervivencia como especie.

Sobre este último punto, García y García, (2001:125) advierten que nosotros, homo sapiens sapiens, “...no somos una especie de trabajadores dentro de un sistema de producción, sino una especie de seres vivos que tiene capacidad de producir", por lo que el currículo no debería sesgarse hacia la satisfacción de las demandas del capital humano provenientes del sistema científico tecnológico.

Con relación a la inconveniencia de sesgar el proceso educativo hacia d desarrollo tecnológico Fainholc (2001) anota la necesidad de:

...reflexionar acerca del futuro incierto que el fanatismo de la magia tecnológica puede ejercer sobre las personas, grupos y el medio ambiente...Los desperdicios técnicos que sobre la faz de la tierra se arrojan y deterioran el Medio Ambiente,... junto a, los resabios tecnológicos convertidos en basura que la sociedad de consumo- y ahora- de información- produce.

También Gorostiaga (2000) al abordar el tema del desarrollo tecnológico apunta: "El significado del progreso basado en el crecimiento material ilimitado es cuestionable por sus implicaciones ecológicas y sociales y por la imposible generalización de este progreso a todos los seres humanos." $Y$ en un tono ampliamente pesimista De la Herrán Gascón (2003) observa que la sociedad occidental, a pesar de su evidente desarrollo, se encuentra carente de ideales siendo catastrófico el creciente panorama de inequidad social y citando a Steiner declara que "vivimos en medio de algo que podemos llamar una enfermedad social cancerosa..." para concluir "No hay norte en la sociedad, no hay norte en la vida. Sin hundirse, la escuela chapotea en medio de la historia"

Martínez (1995) observa que según Erwin Laszlo “...nos encontramos en el período más apasionante y crítico de toda la historia de la humanidad... estamos ante una gran oportunidad pero también ante una gran amenaza..." y Pérez (1998) por su parte; después de citar a científicos (entre ellos varios premios Nóbel) que señalan la problemática del calentamiento global y de la degradación de los ecosistemas que forman la base del bienestar humano; concluye que "... el peligro es serio y no constituye ninguna 'exageración de grupúsculos ecologistas"”

Lozano (2003) nos recuerda que ya Engels el el siglo XIX (Sociedad y Naturaleza) prevenía contra las ilusiones de dominación unilaterales: “... no nos dejemos llevar por el entusiasmo ante nuestras victorias sobre la naturaleza. Después de cada una estas victorias, la naturaleza toma su venganza...". Y el mismo 
Lozano (2003) agrega "El ser humano podrá seguir albergando sus sueños de control y de poder de predicción, pero el caos, la incertidumbre, el azar dice que la mayoría de los sistemas autoorganizados están ligados a innumerables mariposas" y debemos tener presente que "El hombre es, según Nietzsche (citado por Jaspers, en Soriano, 2002::246) el animal no acabado...El hombre, puede no ser como es su esencia...Tiene necesidad de la salvación, la curación, la libertad y el retorno a sí mismo".

La superación de la amenaza que representa el desarrollo tecnológico indiscriminado, planteada por los autores citados, se encuentra en la búsqueda del desarrollo tecnológico modulado por la conciencia de pertenencia a un ecosistema y a una especie, y por tanto, respeto a la vida de ese ecosistema, de la especie y del hombre individual, a través de la educación. Entonces, siguiendo a García y García (2001:369) "La pervivencia de la especie y la construcción del sujeto humano no dependen exclusivamente de la reproducción y la alimentación, sino también del proceso de asimilación cultural que denominamos educación" En ese sentido, Martínez (1995) apunta que "La intervención no puede ser exclusivamente pedagógica,..., pero..., la pedagogía puede desempeñar un papel relevante..." y asevera que "Es necesario apostar pedagógicamente para que la amenaza no sea tal y la oportunidad sea bien aprovechada."

Por su parte, Fernstermacher y Soltis, (1998:86) señalan que a fin de contrarrestar el peligroso impacto para el hombre de la tecnología en el ecosistema se requiere que las virtudes morales e intelectuales sean parte de todo proceso de enseñanza aprendizaje, indicando que dentro de las virtudes morales se puede incluir la honestidad, integridad, disposición imparcial y el trato justo; mientras que entre las virtudes intelectuales están la racionalidad, la amplitud de espíritu, la valoración de las pruebas, la curiosidad, un hábito mental reflexivo y el escepticismo prudente.

Durante los alrededor de 150000 años de existencia del homo sapiens sapiens ha sido la transmisión prominente de conocimientos y destrezas prácticas en el proceso de enseñanza aprendizaje primero y posteriormente en el proceso educativo, las que permitieron su pervivencia y llegar a alcanzar un significativo desarrollo, mediante un dominio de la naturaleza no siempre racional. Pero, "el hombre que medita, dice Rosseau (citado por Cassirer, en Soriano, 2002:220) es un animal depravado: sobrepasar los límites de la vida orgánica no representa una mejora de la naturaleza humana, sino su deterioro".

Para pervivir como especie, el homo sapiens sapiens tiene que moldear su conducta y enmarcarla dentro de una concepción no antropocéntrica sino de pertenencia a un ecosistema, de tal manera que ya no solo se trata de la liberación de los hombres explotados sino también del ecosistema sobre explotado; por ello Pérez (1998) afirma "...la educación ha de contribuir a fundamentar la conveniencia de regirse por otro concepto de eficiencia, que tenga en cuenta las repercusiones tanto para una colectividad dada como para el conjunto de la humanidad y de nuestro planeta."

Al respecto, Paulo Freire (citado por Darcy de Oliveira, 1975) plantea que "...la humanización de los hombres es su liberación permanente y no se lleva a cabo en el interior de sus conciencias, sino en la historia que aquellos deben constantemente hacer y rehacer" y Savater (1996) señala que "Las personas racionales...luchan porque no predominen los dogmas irracionales, las supersticiones, los fanatismos... De modo que la razón es una muestra de convivencia, pero también una fuente de disidencia y de rebelión."

Todas las manifestaciones de la cultura, de las que se apropie el homo sapiens sapiens a través del proceso educativo, deben obligarlo a revelarse ante "la tiranía de la realidad" de la explotación del hombre por el hombre y la sobreexplotación del ecosistema por el hombre. Refiriéndose a los aspectos económicos 
Bautista (2001) apunta que "la desigualdad entre los seres humanos, es una de las incongruencias del planeta, dentro de la historia...", habiendo quienes han señalado (y aun, desgraciadamente lo hacen) que la desigualdad económica es inherente a la condición humana y esencia de la humanidad, fuente de progreso, civilización e historia.

Botkin y otros (1992:30) afirman que "A lo largo de su evolución cultural el hombre se ha adaptado a su entorno, si bien a menudo inconscientemente, configurándolo de forma que quedase garantizada la supervivencia de la especie." Pero para sobrevivir (Barbosa, 2004) "...requerimos información debido a lo complejo y cambiante del ecosistema y de la vida social. Esta situación es tanto más aguda en la sociedad actual "...como consecuencia de los vertiginosos ritmos de cambios en todos los órdenes de la vida..."

A partir de Hiroshima y Nagasaki se demostró que la capacidad tecnológica del homo sapiens sapiens se encuentra en posición de cambiar el ecosistema con la rapidez suficiente para la extinción de la especie y son sus virtudes morales; a las que aluden Fernstermacher y Soltis (1998), las que pueden condicionar una conducta que lo saque de la espiral de violencia que caracteriza a la naturaleza (donde el más fuerte tiene mucho mayor probabilidad de sobrevivir y reproducirse) y permita afirmar BASTA YA cuanto en las sociedades se presenten hechos abominables como la pobreza, el asesinato y la desigualdad social. La alternativa es la extinción.

Estamos en condiciones de tomar conciencia de la amenaza que se cierne sobre nuestra especie y buscar la solución en el proceso educativo que nuevamente se avoque a nuestra subjetividad, esta vez catapultando el cultivo de virtudes morales y aunque ello no es garantía de supervivencia, como no lo es la garra en el león, el tamaño en los elefantes o los dientes en el tiburón, es la esperanza de la humanidad.

El homo sapiens sapiens tiene que asimilar la noción de la imposibilidad de un desarrollo tecnológico que tenga como consecuencia hechos abominables contra el hombre/mujer mismo y/o la desestabilización del ecosistema. Para cambiar esa orientación, sin importar la concepción que se tenga sobre las amenazas que se ciernen sobre la humanidad (consecuencia del desarrollo científico tecnológico referido), ya sea poblacional, armamentista, ambiental, y sin importar el enfoque para superar esa problemática, en lo que hay acuerdo es en que la educación juega y seguirá jugando un rol significativo en la pervivencia de la especie.

Entonces, a través de la cultura, mediante el proceso educativo, único en el homo sapiens sapiens, éste se expresa y toma conciencia de sí mismo, busca nuevos significados, crea obras que le trascienden y cuestiona sus realizaciones, en búsqueda de la pervivencia como especie.

\section{BIBLIOGRAFIA}

ACEVEDO, José. (1998) Análisis de algunos criterios para diferenciar entre ciencia y tecnología. Revista Electrónica de Enseñanza de las Ciencias. Vol. 1, No.6. Disponible en http://www.bib.uab.es/pub/ensenanzadelasciencias/02124521v16n3p409.pdf

Consulta martes 7 de septiembre de 2004 .

ÁNGELA, Piero y ÁNGELA, Alberto. (1999) La extraordinaria historia de la vida. Barcelona, Traducción de: José Maria de Juana y José Ramón. Monreal, España: Grijalbo. 
BAUTISTA García, Antonio (2001). Desigualdades sociales, nuevas tecnologías y política educativa. Enciclopedia Virtual de Tecnología Educativa: Educación y sociedad de la información. Disponible en

http://dewey.uab.es/pmarques/evte2/varios/link externo marco.htm?http://dewey.uab.es/pmarques/EVTE/b autista1.doc

Consulta martes 24 de Agosto de 2004.

BARBOZA, Lidia (2004) Concepciones epistemológicas en la enseñanza. Revista Digital de Educación. Nuevas Tecnologías Contexto Educativo. No. 30, año 6. Disponible en http://contextoeducativo.com.ar/2004/1/nota-05.htm

Consulta: el lunes 16 de agosto de 2004.

BOtKIN, James, ELMANDJRA, Mahdi y MALITZA, Mihaela. (1992) Aprender, horizonte sin límites. México: Santillana.

CASSIRER, E. (1954) Una clave de la naturaleza del hombre: El Símbolo. Revista de Filosofía de Costa Rica. Vol.1, No.4. Recopilación de SORIANO, Oscar y Rápalo, (2002) Filosofía, antología de textos clásicos, Honduras: UPNFM

CAMPS, Victoria. (1997. ¿Tiene sentido educar en valores en las aulas universitarias?. Revista del Colegio de Ingenieros. Recopilación de Gonzáles V. (2004). Modulo 1. Teorías Educativas, Programa de Doctorado: UPNFM.

DARCY DE OlIVEIRA, Rosiska y DOMINICE, Pierre. (1975) Illich-Freire. Pedagogía de los oprimidos. Opresión de la pedagogía. Cuadernos Pedagógicos No.7, España.

DE LA HERRÁN GASCÓN, Agustín. (2003). De la sociedad del acceso a la información a una sociedad mundial y evolutiva. Indagaciones para una reforma profunda de la educación. Enciclopedia Virtual de Tecnología Educativa: Educación y sociedad de la información. Disponible en http://dewey.uab.es/pmarques/EVTE/siherran.pdf

Consulta martes 24 de Agosto de 2004.

DeL VALLE, José. (1822) Memoria sobre la educación. En: Bardales, R. (compilador) (1987) Pensamiento pedagógico hondureño. Tegucigalpa, Honduras: Universitaria.

ESTEBAN SANTOS, Soledad. (2003). La perspectiva de las relaciones ciencia, tecnología y sociedad y su papel en la enseñanza de las ciencias. Revista Electrónica de Enseñanza de las Ciencias. Vol. 2, No.3.Disponible en

http://www.saum.uvigo.es/reec/volumenes/volumen2/Numero3/Art11.pdf

Consulta martes 7 de septiembre de 2004 .

FAINHOLC, Beatriz. (2001). Los nuevos retos de la educación y la formación e la sociedad de la información. Enciclopedia Virtual de Tecnología Educativa: Educación y sociedad de la información. Disponible en http://dewey.uab.es/pmarques/EVTE/fainnuevosretos.doc

Consulta martes 24 de Agosto de 2004. 
FENSTERMACHER, Gary y SOLTIS, Jonas. (1998) Enfoques de la enseñanza.

Argentina: Amorrortu.

GARCíA, Joaquín y GARCíA, Ángel. (2001) Teoría de la educación II. Salamanca, España:

Universidad Salamanca.

GILLARI, Antonio. (2004). Homo sapiens sapiens. ¿El eslabón perdido? Ambiente ecológico, Año 12, No. 88, 2004. Disponible en

http://www.ambiente-ecologico.com/ediciones/2004/088 01.2004/088 Editorial.php3

Consulta martes 8 de febrero de 2004.

GIMENO SACRISTÁN, José y PÉREZ GÓMEZ, Ángel. (1998). Comprender y trasformar la enseñanza. 7ma. ed. España: MORATA.

GONZÁLES, Valentín. (2004) Modulo Teorías educativas del Programa de Doctorado de la UPNFM. Tegucigalpa.

HENRíQUEZ, Juan. (2003). Los imperios del futuro serán los imperios de la mente.

EEUU: Harvard. Disponible en http://www.lugro.org.ar/pipermail/lugro/2004-May/008597.html

Consulta martes 8 de febrero de 2004.

JASPER, Karl. (1965) La pregunta acerca del hombre. Universitas, Vol. III, No.3, 1965. Recopilación de SORIANO, Oscar y RÁPALO, Renán, (2002) Filosofía, antología de textos clásicos, Honduras: UPNFM.

LOZANO, Fernando. (2003) La urdimbre de la eco-información un referente para la educabilidad del sujeto. Revista Digital de Educación. Nuevas Tecnologías, Contexto Educativo. No. 27, Año 5. Disponible en http://contexto-educativo.com.ar/2003/2/nota-01.htm

Consulta martes 17 de agosto de 2004.

LowY, Thomas. (1999). El énfasis en lo cultural. La paradoja de priorizar el desarrollo a los fenómenos que lo producen. OEI-Revista Iberoamericana de Educación - No - 20. Disponible en http://www.campus-oei.org/revista/rie20f.htm Consulta martes 17 de agosto de 2004.

MARTíNEZ, Miguel. (1995) La educación moral: una necesidad en las sociedades plurales y democráticas. Revista Iberoamericana de Educación, No. 27.Disponible en http://www.campusoei.org/oeivirt/rie07a01.htm Consulta martes 17 de agosto de 2004.

MARTínEZ, Miguel. (1999) El enfoque sociocultural en el estudio del desarrollo y educación. Revista electrónica de investigación educativa. Vol. 1, No. 1. Disponible en Disponible en http://redie.ens.uabc.mx/vol1no1/contenido-mtzrod.html . Consulta martes 17 de agosto de 2004.

MEDINA LIBERTY, Adrián. (1999) La naturaleza narrativa de la mente y de la Pedagogía Educar No. 9 Disponible en http://educacion.jalisco.gob.mx/consulta/educar/09/9adrianm.html Consulta miércoles 18 de agosto de 2004.

MOORE, Thomas. (1999). Introducción a la filosofía de la educación. 5 ed. México: Trillas. 
MONDRAGón, Vilma. (1997) El concepto de educación a la luz de la filosofía. Paraninfo [Año IV, No. 8] Universidad Nacional Autónoma de Honduras, Tegucigalpa, Honduras.

ORTIZ, Gustavo. (1997) Lenguaje, significado y validez. Acerca del estatus de la teoría de la educación. Revista La educación, No. I-III, 1997

http://www.iacd.oas.org/La\%20Educa\%20126-128/ortiz.htm

Consulta lunes 21 de octubre de 2002

PÉREZ, Daniel. (1998) El papel de la educación ante las transformaciones científico tecnológicas. Revista Iberoamericana de educación. No. 18.

Disponible en http://www.campus-oei.org/oeivirt/rie18a03.htm

Consulta martes 17 de agosto de 2004 .

RIDLEY, Matt. (1999) Genoma. Madrid, España: Santillana.

SAGAN, Carl. \& DRUYAN, Ann. (1993) Sombras de antepasados olvidados.

Traducción: Miguel Montaner y Maria del Mar Moya (1993)

España: Planeta.

SAVAGE, Jay. (1987) Evolución. México: Continental.

SAVATER, Fernando. (1996). Potenciar la razón. España: El País.

Disponible en http://www.educaciofisica.org/19.potenciarlarazon.htm

Consulta martes 18 de agosto de 2004.

SAVATER, Fernando. (1997) El valor de educar. 2 ed. Barcelona, España: Ariel.

TEJADA FERNÁNDEZ, José. (2001). La educación en el marco de una sociedad global: Algunos principios y nuevas exigencias. Enciclopedia Virtual de Tecnología Educativa: Educación y sociedad de la información. UAB, 2001. Disponible en http://dewey.uab.es/pmarques/EVTE/La\%20educaci\%F3n\%20en\%20una\%20sociedad\%20global.pdf

Consulta martes 24 de Agosto de 2004.

VILA, Ignasi. (1985) Vygotski, 10 años que estremecen la psicología. Cuadernos Pedagógicos. No.121. España

GOROSTIAGA, Xavier. (2000) En busca del eslabón perdido entre educación y desarrollo. Revista Latinoamericana de estudios educativos. Vol. XXX (1)

Disponible en http://www.campus-oei.org/n5087.htm

Consulta lunes 23 de agosto de 2004 . 


\title{
Contactar
}

Revista lberoamericana de Educación

\author{
Principal OEI
}

